\title{
PENGEMBANGAN BAHAN AJAR IPA BERBASIS INKUIRI TERINTEGRASI SETS (SCIENCE, ENVIRONMENT, TECHNOLOGY AND SOCIETY) PADA MATERI SISTEM REPRODUKSI MANUSIA
}

\section{DEVELOPMENT OF SCIENCE, ENVIRONMENT, TECHNOLOGY AND SOCIETY BASED ON SCIENCE INQUIRY IN THE HUMAN REPRODUCTIVE SYSTEM MATERIAL}

\author{
Intan Permatasari ${ }^{1}$, Agus Ramdani ${ }^{2 *}$, Abdul Syukur ${ }^{2}$ \\ ${ }^{1}$ Program Studi Magister Pendidikan IPA, Universitas Mataram, Indonesia \\ ${ }^{2}$ Program Studi Pendidikan Biologi, FKIP, Universitas Mataram, Indonesia \\ *email: aramdani07@unram.ac.id
}

\begin{abstract}
Abstrak: Pembelajaran merupakan kegiatan untuk mencapai tujuan pendidikan dan penentu berhasilnya pendidikan. Pembelajaran adalah aktivitas atau interaksi antar peserta didik, pendidik dan sumber belajar dalam kegiatan belajar mengajar. Dalam hal ini, sumber belajar merupakan sarana penting yang dapat membantu peserta didik dan guru memperoleh informasi dalam kegiatan pembelajaran. Penelitian ini bertujuan untuk mengetahui kelayakan, kepraktisan dan keefektifan bahan ajar IPA berbasis inkuiri terintegrasi Sience, Environment, Technology, Society (SETS) pada materi sistem reproduksi manusiauntuk meningkatkan penguasaan konsep peserta didik. Jenis penelitian ini adalah penelitian dan pengembangan (Research \& Development). Prosedur penelitian menggunakan model pengembangan Dick \& Carey. Teknik pengumpulan data dilaksankan melalui tahap validasi ahli, angket respon guru dan peserta didik serta tes selanjutnya dianalisis dengan teknik kuantitatif dan deskriptif. Hasil penelitian menunjukkan bahwa: (1) bahan ajar berada pada kategori layak dengan rata-rata $80,71 \%$, (2) praktis berdasarkan respon guru dengan rata-rata $80,00 \%$, respon peserta didik dengan rata-rata $80,05 \%$, dan (3) efektif berdasarkan perolehan rata-rata $N$-gain pada kelas eksperimen yang lebih tinggi yaitu sebesar 0,46 (kategori sedang) dan pada kelas kontrol yang memperoleh rata-rata $N$-gain sebesar 0,27 (kategori rendah). Kesimpulan dari hasil penelitian ini adalah bahan ajar IPA berbasis inkuiri terintegrasi SETS pada materi sistem reproduksi manusia layak, praktis dan efektif dalam meningkatkan penguasaan konsep peserta didik.
\end{abstract}

Kata Kunci: Bahan Ajar, Inkuiri, SETS

Abstract: Learning is an activity to achieve educational goals and determine the success of education. Learning is an activity or interaction between students, educators and learning resources in teaching and learning activities. In this case, learning resources are important tools that can help students and teachers obtain information in learning activities. This study aims to determine the feasibility, practicality and effectiveness of science teaching materials based on integrated inquiry Sience, Environment, Technology, Society (SETS) on the material of the human reproductive system to improve students' mastery of concepts. This type of research is research and development (Research \& Development). The research procedure uses the Dick \& Carey development model. Data collection techniques were carried out through expert validation; teacher and student response questionnaires and subsequent tests were analyzed using quantitative and descriptive techniques. The results showed that: (1) teaching materials were in the feasible category with an average of $80.71 \%$, (2) practically based on teacher responses with an average of $80.00 \%$, student responses with an average of $80.05 \%$, and (3) effective based on the average acquisition of $\mathrm{N}$-gain in the higher experimental class that is equal to 0.46 (medium category) and in the control class that obtains an average $\mathrm{N}$-gain of 0.27 (low category). The conclusion from the results of this study is the integrated inquiry-based science teaching materials SETS on human reproductive systems material is feasible, practical and effective in increasing students' mastery of concepts.

Keywords: Teaching Material, Inquiry, SETS

\section{PENDAHULUAN}

Pelaksanaan pembelajaran dituntut untuk menyediakan sumber belajar yang dapat memfasilitasi aktivitas pembelajaran peserta didik, salah satu sumber belajar yang memiliki urgensi dan memiliki pengaruh siginifikan dalam proses pembelajaran adalah bahan ajar [1]. Bahan ajar merupakan salah satu sumber belajar, yang memudahkan peserta didik memperoleh sejumlah informasi, pengetahuan, pengalaman, dan keterampilan dalam proses belajar mengajar [2]. Oleh karena itu, tersedianya bahan ajar yang berkualitas dapat menjadikan proses belajar lebih efektif, efisien, serta dapat meningkatkan mutu pembelajaran [3-4]. Berkaitan dengan hal itu, pembelajaran adalah proses interaksi peserta didik dengan pendidik dan sumber belajar pada suatu lingkungan belajar sehingga terjadi proses perolehan ilmu dan pengetahuan peserta didik [5]. Selain itu, pembelajaran adalah suatu proses dalam rangka mempengaruhi peserta didik agar mampu menyesuaikan diri sebaik mungkin dengan lingkungannya [6]. Dengan 
kata lain, pembelajaran adalah proses membantu peserta didik agar dapat belajar dengan baik [5].

Salah satu permasalahan yang menjadi hambatan di sekolah adalah ketersediaan bahan ajar yang belum memfasilitasi dan melatih peserta didik untuk belajar mandiri, hal ini menyebabkan peserta didik cenderung menunggu guru dalam menemukan konsep pembelajaran sehingga hasilnya belum melatih keaktifan peserta didik [7]. Selain itu, Kekurangaktifan peserta didik ini menyebabkan kesulitan dalam penguasaan konsep dan mengembangkan kemampuan berpikir kritisnya [8]. Dalam hal ini, salah satu model pembelajaran yang mendorong peserta didik untuk aktif menemukan dan membangun pengetahuannya adalah pembelajaran inkuiri dengan SETS [9].

Pembelajaran inkuiri menuntut peserta didik aktif mencari dan menentukan konsep yang mereka butuhkan sehingga peserta didik memperoleh pemahaman yang kuat terhadap materi yang dipelajari [10]. Selain itu, pembelajaran inkuiri merupakan rangkaian kegiatan pembelajaran yang menekankan proses berpikir kritis untuk menemukan jawaban sendiri dari masalah yang dipertanyakan sehingga memperoleh pemahaman terhadap materi yang dipelajari dan mengajak peserta didik secara langsung terlibat ke dalam proses ilmiah dalam kegiatan pembelajaran [11]\&[12]. Penelitian [13]\&[14], menjelaskan bahwa pembelajaran dan penggunaan bahan ajar berbasis inkuiri efektif untuk meningkatkan hasil belajar, keterampilan generik sains, penguasaan konsep dan melibatkan peserta didik aktif dalam menemukan konsep pembelajaran.

Salah satu pendekatan yang memiliki relevansi dengan pembelajaran inkuiri adalah Sience, Environment, Technology, Society (SETS). SETS sendiri merupakan gabungan antara pendekatan konsep, keterampilan proses, CBSA, Inkuiri, diskoveri dan pendekatan lingkungan [11]. Melalui model inkuiri dengan pendekatan SETS, peserta didik diajak untuk melakukan penemuan dan penyelidikan, serta diajak untuk mengkaji teknologi atau aplikasi dari materi yang telah dipelajari ke dalam empat elemen sekaligus yaitu sains, lingkungan, teknologi, dan masyarakat [15]. Selain itu, pembelajaran dengan SETS, membantu peserta didik mendalami dan mengalami sendiri pengetahuan berkaitan dengan materi sains yang dicarinya sehingga pengetahuan itu akan tetap diingat dan hasilnya dapat membantu peserta didik memahami konten dan konsep ilmiah dengan lebih jelas [16] \&[17]. Berdasarkan penelitian [18] \& [19], bahan ajar bervisi SETS layak, praktis dan efektif dalam meningkatkan hasil belajar, kemampuan berpikir kritis dan penguasaan konsep peserta didik.

Berdasarkan data yang diperoleh di MTs Darul Aman Mataram diketahui bahwa nilai hasil belajar IPA peserta didik masih rendah dan masih ada yang belum mencapai KKM yang ditentukan. Hal tersebut berdasarkan hasil nilai ujian akhir semester genap tahun ajaran 2017/2018 dimana peserta didik kelas IX yang berjumlah 58 orang dengan KKM 75, hanya 25 orang yang memperoleh nilai diatas KKM dan 33 orang lainnya tidak mencapai KKM. Dalam hal ini, rendahnya hasil belajar peserta didik berkaitan erat dengan penggunaan model pembelajaran dan sumber belajar (bahan ajar) yang digunakan. Berkaitan dengan hal itu, berdasarkan observasi yang dilaksanakan bahwa: (a) bahan ajar yang digunakan untuk kegiatan pembelajaran masih terbatas pada buku paket IPA dari penerbit, sehingga peserta didik kekurangan referensi dalam mencari tambahan materi, (b) segi materi belum dikemas dengan pendekatan atau model pembelajaran sehingga peserta didik belum terbiasa untuk aktif dan mandiri dalam pembelajaran. Berdasarkan permasalahan yang dikemukakan di atas maka perlu dilakukan pengembangan bahan ajar IPA berbasis inkuiri terintegrasi SETS (Sience, Environment, Technology, Society) pada Materi Sistem Reproduksi Manusia.

\section{METODE}

Penelitian ini adalah penelitian pengembangan (Research \& Development). Prosedur pengembangan mengacu pada model pengembangan Dick \& Carey yang telah diadaptasi dan dimodifikasi oleh peneliti dimana terdapat 10 tahap pengembangan yaitu: (a) analisis kebutuhan dan identifikasi tujuan; (b) analisis instruksional; (c) analisis peserta didik dan konteks; (d) merumuskan tujuan pembelajaran; (e) mengembangkan instrumen penilaian; (f) mengembangkan strategi pembelajaran; (g) mengembangkan dan memilih bahan pembelajaran; (h) merancang dan melakukan evaluasi formatif; (i) melakukan revisi; (j) melakukan evaluasi sumatif [20]. Namun, pengembangan ini hanya dilaksanakan sampai tahap melakukan revisi yaitu dilakukan berdasarkan hasil validasi ahli dan uji coba terbatas.

Subjek dalam penelitian ini adalah peserta didik kelas IX terdiri dua kelas yaitu IXA berjumlah 26 orang sebagai kelas eksperimen dan IXC berjumlah 25 orang sebagai kelas kontrol. Desain uji coba menggunakan desain pretest-posttest control group design. Teknik pengumpulan data dilakukan melalui tahap validasi, angket respon dan tes. Instrumen pengumpulan data yang digunakan untuk menguji kelayakan produk berupa lembar validasi ahli. Kepraktisan produk menggunakan angket respon guru dan peserta didik. Instrumen untuk menguji keefektifan berupa tes penguasaan konsep dalam bentuk pilihan ganda. sejumlah 20 butir yang telah diuji validitasnya oleh ahli.

Data hasil perhitungan kelayakan dan kepraktisan dikonversi dengan kriteria penilaian menurut Riduwan pada Tabel 1 [21]. Analisis data untuk mengetahui keefektifan bahan ajar menggunakan uji $N$-gain. Uji $N$ gain bertujuan untuk mengetahui peningkatan penguasaan konsep peserta didik. Hasil analisis $N$-gain 
dikategorikan menurut Hake yang disajikan pada Tabel 2 [22].

Tabel 1 Kriteria kelayakan dan kepraktisan

\begin{tabular}{cc}
\hline Persentase & Kategori \\
\hline $0-20 \%$ & Tidak layak/praktis \\
$21-40 \%$ & Kurang layak/praktis \\
$41-60 \%$ & Cukup layak/praktis \\
$61-80 \%$ & Layak/praktis \\
$81-100 \%$ & Sangat layak/praktis \\
\hline
\end{tabular}

Tabel 2. Kriteria penilaian $N$-gain

\begin{tabular}{cc}
\hline Indeks Gain & Kategori \\
\hline $\mathbf{0 , 7}<\mathbf{g}=\mathbf{1}$ & Tinggi \\
$\mathbf{0 , 3}<\mathbf{g} \leq \mathbf{0 , 7}$ & Sedang \\
$\mathbf{g}<\mathbf{0 , 3}$ & Rendah \\
\hline
\end{tabular}

\section{HASIL DAN PEMBAHASAN}

Pada penelitian pengembangan model pembelajaran perlu memiliki kriteria kualitas yaitu kevalidan/kelayakan (validity), kepraktisan (practically), dan keefektifan (effectiveness) [23]. Hasil yang dipaparkan pada penelitian ini meliputi hasil uji kelayakan, uji kepraktisan dan uji keefektifan.

\section{Hasil uji kelayakan}

Bahan ajar dan perangkat pendukung yang dihasilkan divalidasi oleh ahli di bidang pendidikan. Penilaian kelayakan bahan ajar yang dikembangkan terdiri dari kelayakan isi, bahasa, penyajian dan kegrafikan sedangkan perangkat pendukung terdiri dari RPP, LKPD dan instrumen soal. Hasil validasi bahan ajar dan perangkat ditunjukkan pada tabel 3 dan 4 .

Tabel 3 hasil validasi bahan ajar

\begin{tabular}{cccc}
\hline No & Komponen & $\begin{array}{c}\text { Skor rata- } \\
\text { rata }\end{array}$ & Kategori \\
\hline 1. & Kegrafisan & $79,99 \%$ & Layak \\
2. & Isi & $80,55 \%$ & Layak \\
3. & Penyajian & $81,66 \%$ & Sangat layak \\
4. & Bahasa & $80,66 \%$ & Layak \\
& rata-rata & $80,71 \%$ & Layak \\
keseluruhan & & \\
\hline
\end{tabular}

Tabel 4 hasil validasi perangkat

\begin{tabular}{lccc}
\hline No & Komponen & $\begin{array}{c}\text { Skor rata- } \\
\text { rata }\end{array}$ & Kategori \\
\hline 1. & RPP & $80,34 \%$ & Layak \\
2. & LKPD & $83,11 \%$ & Sangat Layak \\
3. & Instrumen & $79,34 \%$ & Layak \\
& Soal & & \\
& rata-rata & $80,93 \%$ & Layak \\
& keseluruhan & & \\
\hline
\end{tabular}

Berdasarkan hasil validasi ahli pada Tabel 4 dan Tabel 5 terlihat bahwa rata-rata perolehan skor setiap komponen bahan ajar dan perangkat berada dalam kategori layak dan sangat layak yang artinya dapat digunakan dalam proses pembelajaran dengan sedikir perbaikan berdasarkan saran dari validator. Hasil ini sesuai dengan penelitian [24]\&[25] menyatakan bahwa bahan ajar yang dikembangkan yang mendapatkan kriteria layak dari validator dapat digunakan dalam proses pembelajaran.

Pengembangan bahan ajar berdasarkan pada analisis kompetensi dasar pada konsep sistem reproduksi pada manusia. Penyajian konsep dalam bahan ajar disajikan sesuai dengan tujuan pembelajaran sehingga memudahkan peserta didik memahami konsep yang disampaikan. Bahasa yang termuat dalam bahan ajar disesuaikan pula dengan kemampuan pengguna yaitu peserta didik dan guru. Kegrafikan yang termuat dalam bahan ajar ditinjau dari desain sampul, kesesuain gambar dan ilustrasi serta jenis dan ukuran font yang digunakan dibuat menarik. Beberapa saran yang diberikan validator, diantaranya yaitu tampilan gambar pada bahan ajar harus lebih jelas dan disesuiakan dengan pokok bahasan agar peserta didik tidak keliru, jenis huruf dan ukuran huruf yang digunakan jangan terlalu banyak karena akan membingungkan peserta didik, pada RPP memperhatikan kesesuaian kegiatan pendidik dan peserta didik serta alokasi waktu dengan kegiatan yang akan dilakukan, aktivitas di LKPD lebih disederhanakan agar memudahkan peserta didik, pada instrumen tes penguasaan konsep bahasa dan kalimat diperbaiki sehingga lebih teratur dan menarik.

\section{Hasil uji kepraktisan}

Hasil kepraktisan diperoleh angket respon peserta didik dan guru. Uji ini dilakukan bertujuan untuk mengetahui kepraktisan dan keterbacaan bahan ajar yang dikembangkan [26]. Hasi uji kepraktisan bahan ajar terhadap peserta didik dan guru disajikan pada Tabel 5.

Tabel 5 Hasil Respon Peserta Didik dan Guru

\begin{tabular}{ccc}
\hline Aspek penilaian & Rata-rata & Kategori \\
\hline Respon Guru & $80,00 \%$ & Praktis \\
Respon Peserta didik & $80,05 \%$ & Praktis \\
\hline
\end{tabular}

Penilaian Tabel 5 menunjukkan bahwa respon peserta didik memperoleh skor rata-rata $80,05 \%$ dan guru memperoleh skor rata-rata $80,00 \%$. Hal ini menunjukkan bahwa bahan ajar yang dikembangkan berada dalam kriteria praktis dan terbaca. Hasil uji sesuai dengan penelitian [27] bahwa penggunaan bahan ajar berbasis inkuiri oleh guru dan peserta didik memperoleh respon praktis dalam pembelajaran. Pada pembelajaran menggunakan bahan ajar, peserta didik diberi kegiatan terstruktur berupa lembar aktivitas inkuiri untuk 
menyelidiki dan merumuskan sendiri konsep yang ditemukannya, kemudian peserta didik diberikan tugas untuk mencari masala yang berada dimasyarakat berkaitan dengan sistem reproduksi pada manusia dan dibawa ke dalam kelas untuk dicari penyelesaiannya menggunakan SETS.

\section{Hasil uji keefektifan}

Bahan ajar yang dinyatakan layak dan praktis oleh validator serta praktisi kemudian diujicobakan untuk mengetahui kefeektifan pembelajaran menggunakan bahan ajar yang dikembangkan terhadap peningkatan penguasaan konsep peserta didik. Data hasil perolehan penguasaan konsep peserta didik sebelum dan sesudah perlakuan dapat dilihat pada Tabel 6 .

Tabel 6 Perolehan N-Gain Penguasaan Konsep

\begin{tabular}{ccc}
\hline Aspek & Eksperimen & Kontrol \\
\hline Pretest & 27,5 & 22,4 \\
Postest & 62,5 & 41,4 \\
\hline $\boldsymbol{N}$-gain & 0,46 & 0,27 \\
Kategori & Sedang & Rendah \\
\hline
\end{tabular}

Berdasarkan data yang disajikan pada Tabel 3 dapat diketahui perolehan rata-rata untuk data $\mathrm{N}$-gain penguasaan konsep peserta didik pada kelas eksperimen dengan perolehan sebesar 0,46 (kategori sedang) dan kelas kontrol dengan perolehan sebesar 0,27 (kategori rendah). Berkaitan dengan hal ini, maka nilai penguasaan konsep peserta didik pada kelas eksperimen lebih tinggi dibandingkan dengan kelas kontrol. Tingginya hasil tes penguasaan konsep pada kelas eksperimen ini dapat menginterpretasikan bahwa proses pembelajaran peserta didik menggunakan bahan ajar berbasis inkuiri terintegrasi SETS dapat meningkatkan penguasaan konsep peserta didik. Hal ini sejalan dengan penelitian [28] bahwa ketika peserta didik pada kelas eksperimen diberikan suatu permasalahan maka akan berpengaruh terhadap kemampuannya memberikan jawaban yang lebih baik dibandingkan dengan kelas kontrol, peningkatan penguasaan konsep pada kelas eksperimen juga merupakan implikasi dari pembelajaran berbasis inkuiri.

Penelitian [14] menguatkan bahwa peserta didik yang mendapatkan pembelajaran dengan inkuiri secara keseluruhan menunjukkan penguasaan konsep sainsnya lebih baik, karena semakin banyak keterlibatan peserta didik dalam pembelajaran akan semakin tinggi pula hasil belajar kognitifnya yang berpengaruh pada penguasaan konsep peserta didik. Hal tersebut disebabkan karena melalui langkah-langkah metode ilmiah yang diterapkan dalam pembelajaran dengan inkuiri dapat melatih peserta didik membangun sendiri pengetahuan mereka [29]. Selain itu, melalui pembelajaran terintegrasi SETS, didapatkan hasil belajar kelas eksperimen lebih baik dibandingkan kelas kontrol yaitu pada penilaian kognitif, sikap dan keterampilan [30]. Pembelajaran dengan SETS juga dapat meningkatkan ketuntasan belajar, aktivitas dan meningkatkan penguasaan konsep peserta didik [31]\&[19]. Berkaitan dengan hal itu, berhasil tidaknya proses dan hasil belajar dipengaruhi kesiapan guru dalam mengajar serta model atau pendekatan pembelajaran yang digunakan [32].

\section{KESIMPULAN}

Berdasarkan hasil penelitian dan pembahasan yang telah uraikan, dapat disimpukan bahwa bahan ajar IPA berbasis inkuiri terintegrasi SETS pada materi sistem reproduksi manusia yang telah dikembangkan layak, praktis dan efektif meningkatan penguasaan konsep peserta didik. Hal ini, berdasarkan penilaian ahli yang memperoleh kategori baik dan layak digunakan dalam pembelajaran IPA. Disamping itu berdasarkan respon peserta didik dan respon guru setelah proses pembelajaran menggunakan bahan ajar yang dikembangkan memperoleh kategori baik sehingga dapat dinyatakan penggunaan bahan ajar praktis dalam pembelajaran. Adapun perbedaan hasil uji $\mathrm{N}$-gain kelas eksperimen yang mengalami peningkatan yaitu dengan kategori sedang dan kelas kontrol memperoleh kategori rendah yang berarti bahan ajar berbasis inkuiri terintegrasi SETS dapat mengoptimalkan penguasaan konsep peserta didik.

\section{DAFTAR PUSTAKA}

[1] Windyariani, S. Setiono. \& Sutisnawati, A. 2016. Pengembangan Bahan Ajar Berbasis Konteks dan Kreativitas untuk Melatihkan Literasi Sains Peserta Didik Sekolah Dasar. Jurnal Bioedukatika, 4(2):1925.

[2] Farda, J, U. Binadja, A.\& Purwanti, E. 2016. Validitas Pengembangan Bahan Ajar IPA Bervisi SETS. Journal of Primary Education, 5(1):36-41.

[3] Ningtyas, E, A., Sumarni, W., \& Christijanti, W. 2014. Pengembangan Modul IPA Terpadu Berbasis SETS Dengan Tema Hujan Asan Untuk Kelas VII SMP. Unnes Science Education Journal, 3(1): 438444.

[4] Ikhsan, M., Suratno., \& Prayitno, B. A. 2016. Pengembangan Modul Berbasis Inkuiri Terbimbing Pada Materi Sistem Gerak Manusia Untuk Meningkatkan Hasil Belajar Peserta didik Kelas XI MIA SMA Negeri 1 Wera Kabupaten Bima Nusa Tenggara Barat. Jurnal Inkuiri, 5(1): 133-142.

[5] Rakhmawati, S., Muspiroh, N., \& Azmi, N. 2016. Analisis Pelaksanaan Kurikulum 2013 Ditinjau Dari Standar Proses Dalam Pembelajaran Biologi Kelas $X$ Di Sma Negeri 1 Krangkeng. Scientiae Educatia: Jurnal Sains dan Pendidikan Sains, 5(2): 156-164.

[6] Suardi, M. 2018. Belajar \& Pembelajaran. Yogyakarta: Deepublish.

[7] Deswita, D. \& Hufri. 2018. Validasi Bahan Ajar Fisika Berbasis Inkuiri Pada Materi Hukum Newton 
Tentang Gerak Dan Gravitasi Untuk Meningkatkan Literasi Sains. Pillar of Physics Education. 11(3):153-160.

[8] Kurniawati, I, D., Wartono., \& Diantoro M. 2014. Pengaruh Pembelajaran Inkuiri Terbimbing Integrasi Peer Instruction Terhadap Penguasaan Konsep Dan Kemampuan Berpikir Kritis Siswa. Jurnal Pendidikan Fisika Indonesia, 10: 36-46.

[9] Umami, R., \& Jatmiko, B. 2013. Penerapan Model Pembelajaran Inkuiri Dengan Pendekatan SETS (Sicence, Environment, Technology and Society) Pada Pokok Bahasan Fluida Statis Untuk Meningkatkan Keterampilan Berpikir Kritis Peserta didik Kelas XI SMA Negeri 1 Gedangan. Jurnal Inovasi Pendidikan Fisika, 2(3):61-69

[10] Novitaningrum, M. Parmin. \& Pamelasari, D, S. 2014. Pengembangan Handout IPA Terpadu Berbasis Inkuiri Pada Tema Mata Untuk Kelas IX Peserta didik MTs Al-Islam Sumurejo. Unnes Science Education Journal, 3(2):542-548

[11] Deswita, D. \& Hufri. 2018. Validasi Bahan Ajar Fisika Berbasis Inkuiri Pada Materi Hukum Newton Tentang Gerak Dan Gravitasi Untuk Meningkatkan Literasi Sains. Pillar of Physics Education, 11(3):153-160.

[12] Agustanti, T.H. 2012. Implementasi Metode Inquiry Untuk Meningkatkan Hasil Belajar Biologi. Jurnal Pendidikan IPA Indonesia, 1 (1): 16-20.

[13] Hamdani, F, V. 2017. Pengembangan Bahan Ajar Berbentuk LKS Berbasis Inkuiri untuk Meningkatkan Keterampilan Generik Sains dan Hasil Belajar Termokimia Siswa SMA. Pascasarjana. Unram.

[14] Susilawati., Susilawati., \& Sridana N. 2015. Pengaruh Model Pembelajaran Inkuiri Terbimbing terhadap Penguasaan Konsep Sains Ditinjau dari Kemampuan Awal Peserta didik. Journal Penelitian Pendidikan IPA, 1(2):102-110.

[15] Khasanah, N. 2015. SETS (Science, Environmental, Technology and Society) Sebagai Pendekatan Pembelajaran IPA Modern pada Kurikulum 2013. Prosiding Seminar Nasional Konservasi Pemanfaatan Sumber Daya Alam: 270-277.

[16] Yuniastuti, E. 2015 Pengaruh Model Pembelajaran SETS (Science, Environment, Technology and Society) Terhadap Hasil Belajar Biologi Peserta didik Kelas VII SMP Kartika V-1 Balikpapan. Jurnal Sains Terapan, 2(1): 72-78

[17] Zhang, T., Asher, E., Zhang, M., \& Yang, J. 2017. Thinking about Science: Understanding the Science, Technology, Society and Environment Education of Canada. International Journal of Education and Social Science, 4(2): 15-20.

[18] Nugraha, A, D., Binadja, A., \& Supartono. 2013. Pengembangan Bahan Ajar Reaksi Redoks Bervisi SETS, Berorientasi Konstruktivistik. Journal of Innovative Science Education, 2(1): 27-34.
[19] Wijayanti, R, S, M., Binandja, A., \& Haryani, S. 2013. Pengembangan Model Pembelajaran Larutan Penyangga Berbasis Masalah Bervisi SETS. Journal Of Innovative Science Education, 2(1):1-6.

[20] Dick, W., Carey, L., \& Carey, J, O. 2009. The Systematic Design of Instruction. Universitas of South Florida: Emeritus.

[21] Riduwan, 2018. Dasar-dasar Statistika. Bandung: Alfabeta.

[22] Hake, R.R. 1999. Analyzing Change/Gain Score.USA: Dept.Of Physics Indiana University.

[23] Nieveen, N. 1999. Prototyping to Reach Product Quality.Design Approaches and Tools in Education and Training. London: Kluwer Academic Publisher.

[24] Farda, J, U. Binadja, A.\& Purwanti, E. 2016. Validitas Pengembangan Bahan Ajar IPA Bervisi SETS. Journal of Primary Education. 5(1):36-41.

[25] Amin \& Kholiqul. A. 2016. Analisis Bahan Ajar Modul Statistika Pada Program Studi Pendidikan Matematika IKIP PGRI Bojonegoro. Jurnal Edutama, 7 (6): 1-9.

[26] Nisyah, M., Gunawan., Harjono., A \& Kusdiastuti., M. 2019. Perangkat Pembelajaran Model Inkuiri Dipadu Advance Organizer Untuk Meningkatkan Penguasaan Konsep Dan Kemampuan Pemecahan Masalah Fisika Siswa. Jurnal Pijar MIPA, 14(2):16.

[27] Hasanah, J., Jamaluddin., \& Prayitno., H, G. 2019. Bahan Ajar IPA Berbasis Inkuiri Terstruktur Untuk Meningkatkan Literasi Sains Peserta Didik SMP. Jurnal Pijar MIPA, 14(2):1-7.

[28] Hasbi, A, M., Kosim., \& Gunawan. 2015. Pengembangan Alat Peraga Listrik Dinamis (Apld) Berbasis Inkuiri Untuk Meningkatkan Penguasaan Konsep Peserta didik. Jurnal Penelitian Pendidikan IPA (JPPIPA), 1(1): 1-5.

[29] Senjaharmini, A, D., Jufri, W, A., \& Jamaluddin. 2019. Efektivitas Bahan Ajar IPA Berbasis Inkuiri Terbimbing (BAIPAIT) Untuk Meningkatkan Kemampuan Berargumen Peserta Didik. Jurnal Pijar MIPA, 14(2):1-5.

[30] Winarti, Y., Indriyanti, R, D., \& Rahaya, S, E. 2016. Pengembangan Bahan Ajar Ekologi Kurikulum 2013 Bermuatan SETS melalui Penerapan Model Based Learning. Unnes Science Educational Journal, 44 (1): 14-23.

[31] Minarti, I.B., Susilowati, S.M.E., \& Indriyanti, D, R. (2012). Perangkat Pembelajaran IPA Terpadu Bervisi SETS Berbasis Edutainment Pada Tema Pencernaan. Journal of Innovative Science Education, 1(2):105-111.

[32] Makhrus, M., Harjono, A., Syukur, A., Bahri, S., \& Muntari. 2019. Analisis Rencana Pelaksanaan Pembelajaran (RPP) Terhadap Kesiapan Guru Sebagai "Role Model" Keterampilan Abad 21 Pada Pembelajaran IPA SMP. JPPIPA, 5(1): 66-72. 